\title{
Aplikasi Pengenalan Rambu Lalu Lintas Berbasis Android
}

\author{
Herman Abdul Rohman', Ummu Radiyah², Andry Maulana ${ }^{3}$ \\ Program Studi Teknik Informatika, STMIK Nusa Mandiri ${ }^{(1,2,3)}$ \\ Jl. Damai No. 8, Warung Jati Barat (Margasatwa), Pasar Minggu, Jakarta Selatan, Tlp. 021-78839513 \\ e-mail: herman.abdulrohman@gmail.com ${ }^{1}$, ummu.urd@ nusamandiri.ac.id ${ }^{2}$, andry.ayz@ nusamandiri.ac.id ${ }^{3}$
}

\begin{abstract}
One of the problems faced in big cities in Indonesia is the problem of traffic. This proven by the indication of the number of traffic accidents is always increasing. This situation is caused by several factors, one of which is due to the lack of awareness and knowledge of people towards traffic signs. The development of technology at this time especially smartphone users more and more especially Android based smartphone users because the current price is quite affordable for all people of Indonesia, therefore the author makes a mobile application using the Android Studio software titled Android-Based Traffic Sign Recognition Application using sequential algorithm method, with the Android-Based Traffic Signs Recognition application that the author made, it is hoped that the public can easily learn about traffic signs in Indonesia only with a hand, so it is hoped that in the future it can be a solution in reducing the number of traffic accidents.
\end{abstract}

Keywords: Traffic, Signs, Android, Traffic Sign

\section{PENDAHULUAN}

Rambu lalu lintas merupakan salah satu dari perlengkapan jalan yang berupa lambang, huruf, angka, kalimat atau perpaduan diantaranya sebagai peringatan, larangan, perintah, atau petunjuk bagi pemakai jalan raya. Lalu lintas merupakan hal yang penting untuk meningkatkan pergerakan masyarakat sehingga negara merasa penting untuk mengaturnya sesuai dengan perkembangan zaman, agar terjaganya hak-hak masyarakat dalam menggunakan jalan. Indonesia sebagai salah satu negara berkembang di dunia dengan tingginya tingkat pertumbuhan penduduk yang berkaitan dengan tingginya pengguna kendaraan bermotor di Indonesia yang berdampak juga pada tingginya angka kecelakaan bermotor di Indonesia yang salah satunya disebabkan oleh pelanggaran rambu lalu lintas (Hasibuan, JP., Eko Handoyo, S., 2014)

Peraturan berkendaraan bermotor telah diatur dalam Undang-undang No 22 tahun 2009, tingginya kecelakaan kendaraan bermotor di Indonesia bisa dilihat dari data Ditlantas Polda Metro Jaya bahwa jumlah kejadian kecelakaan di tahun 2018 lebih tinggi dibandingkan dengan tahun 2017, pada tahun 2017 tercatat 222 orang meninggal dunia sedangkan pada tahun 2018 meningkat menjadi 276 orang meninggal dunia (Ditlantas Polda Metro Jaya, 2018). Mengacu pada hal tersebut penulis berasumsi bahwa terdapat permasalahan dalam hal kendaraan bermotor di jalan raya, salah satu langkah alternatif untuk meminimalisir kejadian kecelakaan di jalan raya adalah dengan pendidikan usia dini terkait dengan peraturan berlalu lintas. Pentingnya pendidikan usia dini adalah sebagai pembentuk karakter anak, dengan pembentukan karakter yang baik diharapkan sebagai jembatan penghubung anak di masa depan (Sudarsana, I. K., 2017).

Menurut Undang-undang No 20 tahun 2003, bab $\mathrm{V}$, pasal 8 tentang hak dan kewajiban masyarakat menyatakan bahwa, masyarakat berhak berperan serta dalam perencanaan, pelaksanaan, pengawasan, dan evaluasi program pendidikan. dan Bab III, pasal 4 bahwa pendidikan diselenggarakan dengan memberi keteladanan, membangun kemauan, dan mengembangkan kreativitas peserta didik dalam proses pembelajaran (www.kelembagaan.ristekdikti.go.id, 2016). Mengacu dengan uraian tersebut, memacu penulis untuk berkarya terkait dengan bagaimana mengurangi kejadian kecelakaan berlalu lintas di masa yang akan datang, dengan cara memberikan pendidikan di usia dini melalui media pembelajaran pengenalan rambu lalu lintas berbasis mobile.

Berdasarkan latar belakang masalah di atas, maka rumusan masalah dalam penelitian ini adalah bagaimana membuat suatu aplikasi mobile tentang rambu lalu lintas untuk meminimalisir pelanggaran lalu lintas dan sebagai sarana investasi jangka panjang dengan memperkenalkan rambu lalu lintas di pendidikan usia dini. Penulis bertujuan dengan aplikasi mobile ini sebagai salah satu investasi jangka panjang terkait dengan sadar berlalu lintas di masyarakat dengan melalui pendidikan usia dini karena pada usia dini adalah masa pembentukan karakter dan perlu digaris bawahi bahwa setiap warga negara berhak untuk berpartisipasi dalam penyelenggaraan 
pendidikan sehingga melalui pembuatan aplikasi pengenalan rambu-rambu lalu lintas berbasis mobile ini, penulis telah ikut serta dalam penyelenggaraan pendidikan yang telah diamanatkan di Undang-undang No 20 tahun 2003, bab V pasal 8 tentang hak dan kewajiban masyarakat.

\section{LANDASAN TEORI}

\subsection{Definisi Android}

Android adalah sistem operasi yang dikeluarkan oleh Google yang dibuat khusus untuk smartphone dan tablet (Permana, Sidiq\&Imaduddin,Ahmad, 2018). Android memiliki fitur-fitur yang sangat canggih dan tampilan yang bagus sehingga mampu memanjakan penggunanya seperti fungsinya sebagai alat multimedia yang dapat memutar musik dan video serta memiliki perangkat keras seperti accelerometer, gyroscope dan sensor lainnya.

\subsection{Definisi Java}

Menurut Sianipar (2018:1) "Bahasa pemrograman Java sangat popular digunakan dalam pengembangan aplikasiaplikasi tingkat tinggi, Java tidak lagi hanya untuk pemograman web, namun juga bisa digunakan untuk aplikasi standalone, desktop, server, dan peralatan-peralatan bergerak (mobile)".

\subsection{Android Studio}

Menurut (Makiolor, Sinsuw, \& Najoan, 2017)

"Android Studio adalah sebuah IDE (Integrated Development Environment) yang bisa digunakan untuk pengembangan aplikasi Android, dan dikembangkan oleh google". Android Studio adalah hasil pengembangan dari Eclipse IDE, terdapat fitur-fitur baru dalam pengembangan tersebut diantaranya adalah Menggunakan Gradle-based build system yang fleksibel, dapat membangun multiple APK (format berkas), Template support untuk Google Service dan berbagai macam tipe perangkat dan layout editor yang lebih bagus.

\subsection{Adobe Illustrator}

Menurut Jubilee Enterprise (2018: 1) "Adobe Illustrator adalah software desain grafis yang dimanfaatkan untuk membuat gambar dan ilustrasi berbentuk vektor". Keunggulan yang dimiliki Objek vektor adalah dalam hal ketajaman gambar, namun objek vektor memiliki suatu kekurangan yaitu tidak bisa menangani objek dengan tampilan realistis seperti foto. Adobe Illustrator dimanfaatkan untuk membuat gambar objek-objek vektor.

\section{METODE PENELITIAN}

Dalam perancangan program aplikasi ini, menggunakan beberapa metode dalam pelaksanaannya. Adapun metode-metode tersebut adalah sebagai berikut:

\subsection{Teknik Pengumpulan Data}

1. Observasi

Tahap untuk memperoleh data terkait tentang tingginya para pengendara bermotor melakukan pelanggaran lalu lintas dan dampak dari pelanggaran tersebut.

2. Wawancara

Melakukan tanya jawab dengan masyarakat khususnya anak-anak usia dini terkait tentang kebutuhan akan data dalam perancangan aplikasi mobile pengenalan rambu lalu lintas di usia dini.

3. Studi Pustaka.

Metode pustaka yaitu dengan cara membaca buku-buku, internet dan artikel dari jurnaljurnal yang berkaitan, sehingga menjadi acuan bagi penulis dalam penelitian ini.

\subsection{Metode Pengembangan Aplikasi}

Metode Pengembangan Aplikasi ini menggunakan pendekatan prototype. Prototype adalah sebuah metode pengembangan software yang banyak digunakan pengembang agar dapat saling berinteraksi dengan user selama proses pembuatan sistem (Rusdiansyah, R., 2019) sehingga dalam proses pengembangan aplikasi disesuaikan dengan kebutuhan pengguna yang terus menerus diperbaiki melalui kerjasama antara pengguna dan pengembang aplikasi.

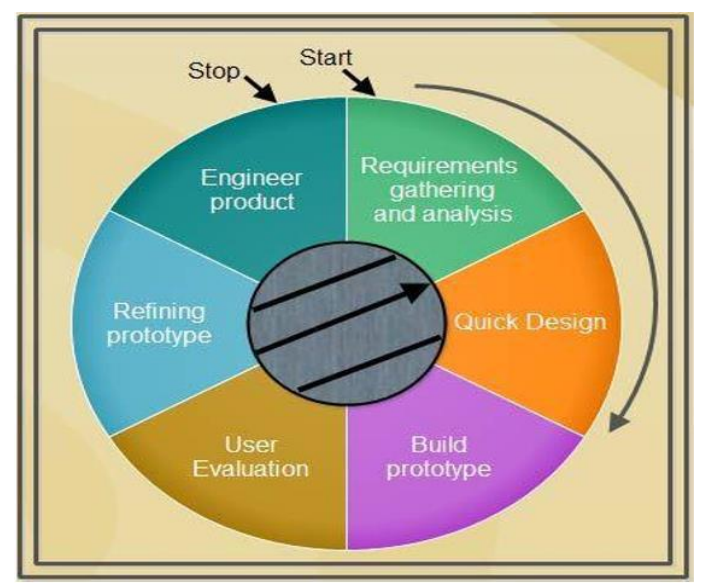

Gambar 1. Model Prototype 
Berikut ini adalah tahap-tahapan model prototype yang penulis kembangkan:

\section{a. Requirements gathering and analysis}

Dalam pengembangan aplikasi ini dimulai dengan analisis kebutuhan dan persyaratan sistem. Wawancara dengan pengguna sangat diperlukan untuk mengetahui kebutuhan pengguna serta mendefinisikan secara rinci persyaratan sistem dalam aplikasi mobile yang akan diimplementasikan.

b. Quick design

Apabila analisa kebutuhan dan persyaratan sistem aplikasi mobile sudah diketahui oleh pengguna, langkah selanjutnya adalah membuat desain awal atau desain cepat, dalam hal ini desain hanya bersifat sementara dan tidak rinci, hanya mencakup aspek penting dari aplikasi mobile yang akan diimplementasikan, dalam proses desain awal ini menggunakan software pengolah gambar Adobe Illustrator CS5.1.

c. Build prototype

Informasi yang dikumpulkan dari desain awal atau desain cepat dimodifikasi dan diimplementasikan ke dalam program perangkat lunak, termasuk di dalamnya adalah fase pengkodean sampai menjadi sebuah aplikasi mobile atau disebut juga sebagai prototype pertama, dalam pembuatan prototype pertama ini menggunakan software Android Studio 3.1.3.

d. User evaluation

Selanjutnya, aplikasi mobile atau prototype pertama dipresentasikan kepada pengguna untuk evaluasi menyeluruh untuk mengenali kekuatan dan kelemahannya dari aplikasi mobile atau prototype tersebut, serta komentar dan saran dikumpulkan dari pengguna dan diberikan kepada pengembang.

e. Refining prototype

Setelah pengguna mengevaluasi aplikasi mobile atau prototype, dan apabila pengguna tidak sesuai atau tidak puas, maka aplikasi mobile atau prototype tersebut harus segera disempurnakan dan dikembangkan sesuai dengan komentar dan saran dari pengguna. Setelah disempurnakan dan dikembangkan aplikasi mobile atau prototype baru tersebut dipresentasikan dan dievaluasi lagi oleh pengguna, proses ini terus berlanjut sampai sesuai dengan persyaratan oleh pengguna.

f. Engineer product

Tahapan akhir adalah evaluasi secara menyeluruh diikuti oleh pemeliharaan rutin.

\section{HASIL DAN PEMBAHASAN}

Berikut ini hasil implementasi aplikasi yang telah dilakukan. Pada tahap ini dijelaskan hasil implementasi system.

\section{Implementasi Tampilan Menu Utama}

Pada tampilan menu utama, user dapat memilih menu utama yang diinginkan, serta lanjut untuk masuk ke interface berikutnya, Pada gambar 2 adalah implementasi dari tampilan menu utama yang terdiri atas menu Rambu Peringatan, Rambu Larangan, Rambu Perintah, Rambu Petunjuk Arah, Rambu tambahan, Rambu Rute Jalan, Petunjuk pembuatan SIM, Quiz, dan Help.

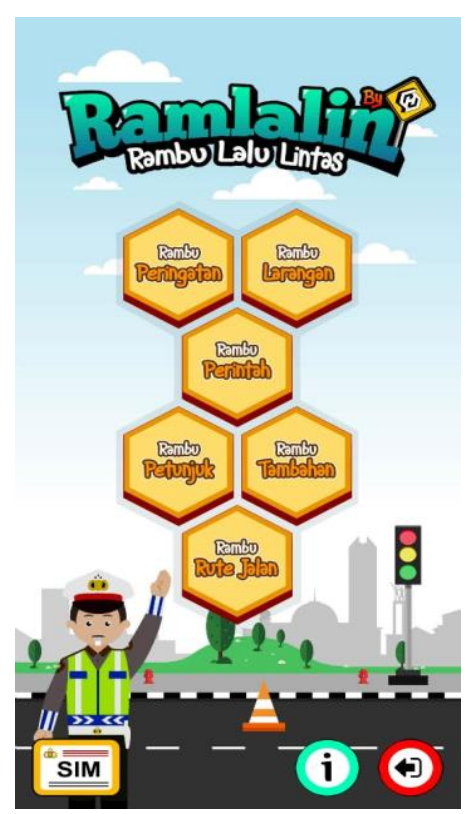

Gambar 2. Implementasi Tampilan Menu Utama

2. Implementasi Tampilan Menu Rambu Peringatan

Pada tampilan menu rambu peringatan terdapat konten terkait dengan rambu-rambu peringatan dalam berlalu lintas, terdapat tombol lanjut untuk masuk ke interface berikutnya, Pada gambar 3 adalah implementasi dari tampilan menu rambu peringatan. Rambu-rambu ini ditampilkan dengan gambar yang sangat jelas dan menarik sehingga user dalam hal ini masyarakat atau anak-anak usia dini dapat menggunakan atau melihat rambu-rambu dengan sangat mudah dipahami karena disertai dengan deskripsi di setiap gambarnya. 


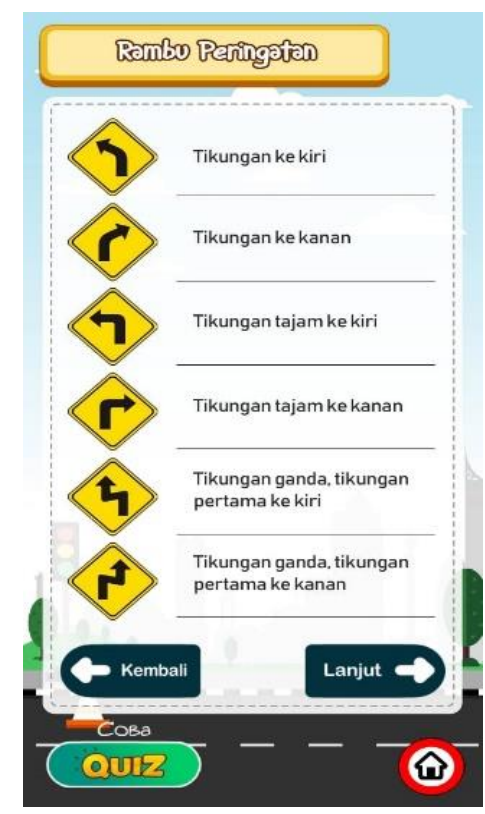

Gambar 3. Implementasi Tampilan Menu Rambu Peringatan

3. Implementasi Tampilan Menu Kuis Rambu Peringatan

Pada tampilan menu kuis rambu peringatan terdapat konten terkait dengan pertanyaan kuiz menebak rambu-rambu peringatan dalam berlalu lintas, diakhiri dengan nilai dari jawaban pertanyaan-pertanyaan kuiz tersebut, Pada gambar 4 adalah implementasi dari tampilan menu kuis rambu peringatan:

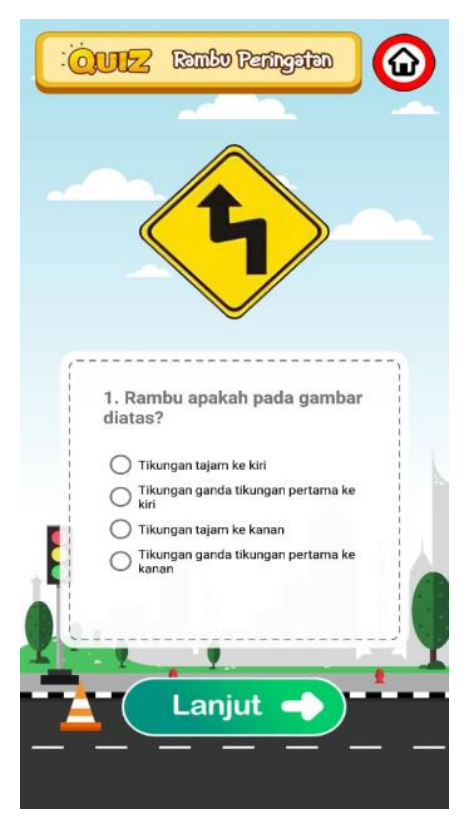

Gambar 4. Implementasi Tampilan Menu Kuis Rambu Peringatan
4. Implementasi Tampilan Menu SIM

Pada tampilan menu SIM terdapat konten terkait dengan syarat pembuatan SIM, Pada gambar 5 adalah implementasi dari tampilan menu SIM

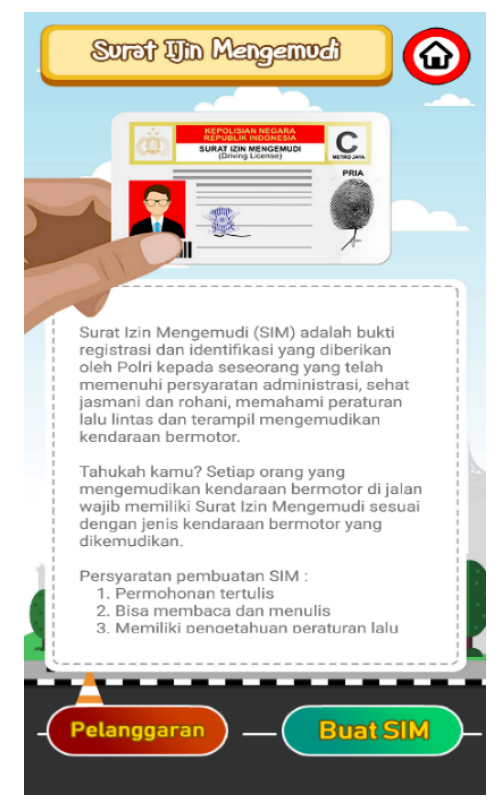

Gambar 5. Implementasi Tampilan Menu SIM

5. Implementasi Tampilan Menu Pelanggaran Pada tampilan menu pelanggaran terdapat konten terkait dengan pengemudi yang melanggar peraturan lalu lintas, Pada gambar 6 adalah implementasi dari tampilan menu pelanggaran:

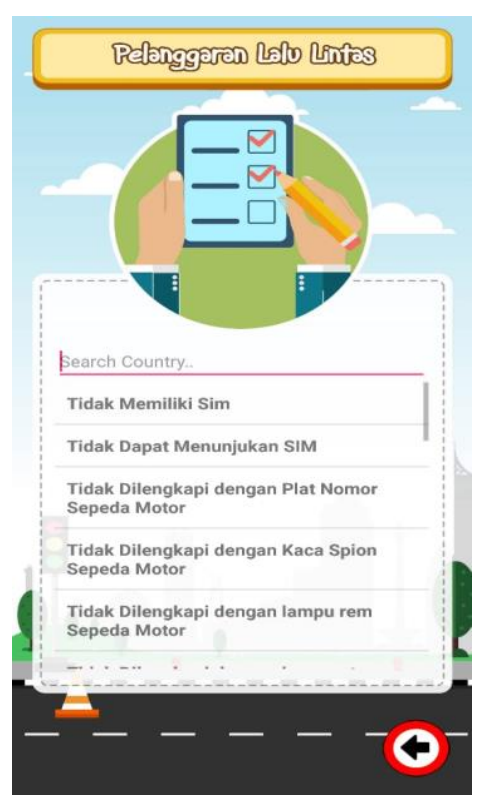

Gambar 6. Implementasi Tampilan Menu Pelanggaran 
6. Implementasi Tampilan Menu Buat SIM

Pada tampilan menu Buat SIM terdapat konten terkait lokasi pembuatan SIM yang mencakup wilayah Jakarta, Bogor, Depok, Tangerang dan Bekasi, Pada gambar 7 adalah implementasi dari tampilan menu buat SIM.

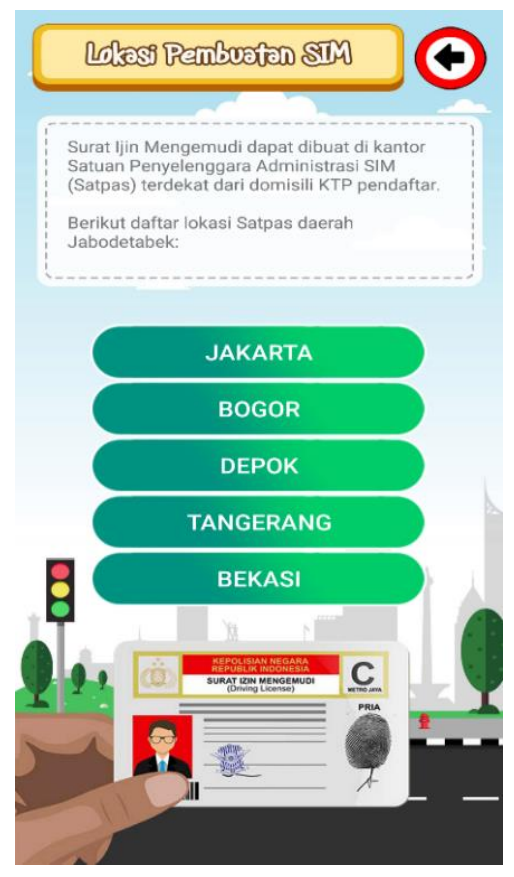

Gambar 7. Implementasi Tampilan Menu Buat SIM

7. Implementasi Tampilan Menu Peta Pembuatan SIM

Pada tampilan menu peta lokasi pembuatan SIM terdapat konten lokasi titik koordinat tempat pembuatan SIM yang mencakup wilayah Jakarta, Bogor, Depok, Tangerang dan Bekasi, Pada gambar 8 adalah implementasi dari tampilan menu peta lokasi pembuatan SIM.

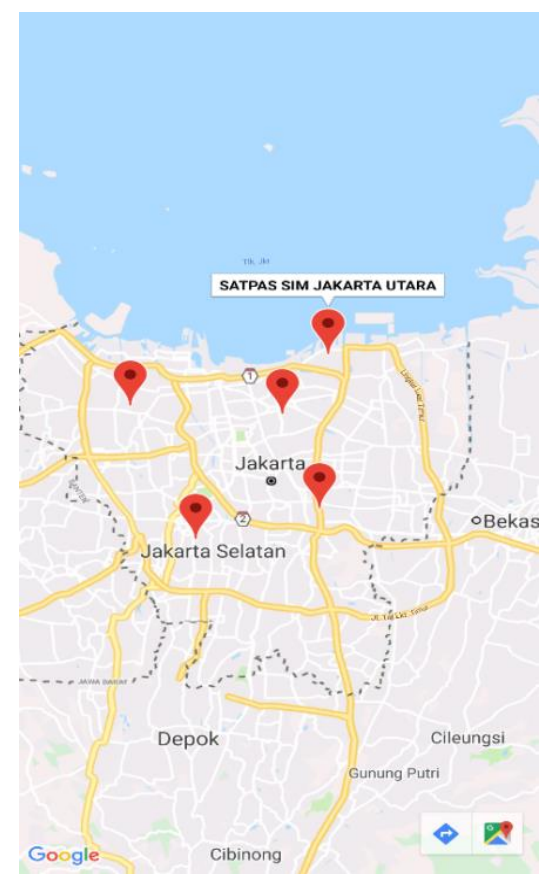

Gambar 8. Implementasi Tampilan Menu Peta Pembuatan SIM

\section{PENUTUP}

\subsection{KESIMPULAN}

Berdasarkan pembahasan dan hasil yang diperoleh, maka dapat ditarik kesimpulan sebagai berikut:

1. Pengembangan aplikasi pengenalan rambu lalu lintas merupakan aplikasi berbasis android, yang bisa digunakan kapanpun dan oleh siapapun karena dengan perkembangan teknologi mobile yang semakin maju dengan sentuhan sistem multimedia yang membuat tampilan lebih menarik dan mudah dipahami dengan baik oleh anak-anak usia dini.

2. Pengembangan aplikasi pengenalan rambu lalu lintas ini ditujukan khususnya untuk anak usia dini, dan masyarakat pada umumnya.

3. Pengembangan aplikasi pengenalan rambu lalu lintas ini bertujuan untuk ikut serta berpartisipasi dalam menurunkan kejadian kecelakaan lalu lintas di jalan raya, dengan pengenalan rambu lalu lintas kepada masyarakat yang dikemas dengan menarik dan persuasif.

\subsection{SARAN}

Saran pengembangan untuk penelitian lebih lanjut untuk aplikasi pengenalan rambu-rambu lalu lintas ini adalah sebagai berikut: 
1. Menambahkan game yang dapat dimainkan oleh pengguna agar dapat lebih menarik.

2. Ditambahkan menu data update kecelakaan sebagai pemberitahuan kepada pengguna agar lebih berhati-hati dan menaati peraturan ramburambu lintas.

\section{REFERENSI}

[1] Baskoro, Rangga, 2018, Jumlah Kecelakaan Lalu Lintas Tahun 2018 Meningkat Dibandingkan Tahun Lalu https://wartakota.tribunnews.com/2018/12/17/ju mlah-kecelakaan-lalu-lintas-tahun-2018meningkat-dibandingkan-tahun-lalu.

[2] Direktorat Lalu Lintas Polda Metro Jaya. 2018. Data Kecelakaan Lalu Lintas dan Pelanggaran Lalu Lintas Kota Jakarta Tahun 2017- 2018.

[3] Enterprise, J. (n.d.). 2018. Otodidak Adobe Illustrator. Elex Media Computindo: Jakarta

[4] Gurning, E.H (2013), Implementasi UndangUndang Nomor 22 Tahun 2009 Tentang Lalu Lintas dan Angkutan Jalan Raya, https://www.bantuanhukum.or.id/web/implemen tasi-undang-undang-nomor-22-tahun-2009tentang-lalu-lintas-dan-angkutan-jalan-raya/

[5] Hasibuan, JP., Eko Handoyo, S. (2014). Peran Sekolah dalam Meningkatkan Kesadaaran Hukum Berlalu Lintas Siswa SMA Negeri 3 Cirebon, Unnes Civic Education Journal 3(2), 1-9. http://journal.unnes.ac.id/sju/index.php/ucej

[6] Makiolor, A. A. A., Sinsuw, A. A. E., \& Najoan, X. B. N. (2017). Rancang Bangun Pencarian Rumah Sakit, Puskesmas dan Dokter Praktek Terdekat di Wilayah Manado Berbasis Android. E-Journal Teknik Informatika Universitas Sam Ratulangi, 10(1), 1-10.

[7] Permana, Sidiq, Imaduddin,Ahmad. (2018). Menjadi Android Developer Expert. Dicoding, Android Associate: Bandung.

[8] Rusdiansyah, R. (2019). Membangun Prototype Sistem Informasi Arsip Elektronik Surat Perjanjian Kerjasama Pada Business Support Departement. Jurnal Pilar Nusa Mandiri, $14(2)$, https://doi.org/10.33480/pilar.v14i2.903

[9] Sianipar. (2018). Dasar Analisis Dan Perancangan Pemrograman Berorientasi Objek Menggunakan java. Andi Publisher: Yogyakarta

[10] Sudarsana, I. K. (2017). Membentuk Karakter Anak sebagai Generasi Penerus Bangsa Melalui Pendidikan Anak Usia Dini. Jurnal Purwadita, 1(1), 41-48

[11] Undang-undang No.22 Tahun 2009 Tentang Lalu Lintas dan Angkutan Jalan

[12] Undang-undang No 20 tahun 2003 www.kelembagaan.ristekdikti.go.id. 2016 